\title{
O CONTROLE E A IMPLEMENTAÇÃO DO DIREITO À SAÚDE: A JURISPRUDÊNCIA DA ÁFRICA DO SUL
}

\author{
Karinne Fontenele Sampaio ${ }^{86}$
}

Recebido em: 30/09/2016

Aprovado em: 10/12/2016

\begin{abstract}
RESUMO
O presente estudo objetiva examinar o controle e a implementação do direito à saúde pelo poder judiciário da África do Sul e, em especial, pela Corte Constitucional do país. Para tanto, será realizada breve abordagem acerca do contexto histórico da nova democracia sulafricana e os delineamentos do sistema judicial que com ela advieram. O sistema judicial sul-africano será exposto a fim de possibilitar uma melhor compreensão acerca dos casos examinados e, por fim, analisarse-á a jurisprudência da Corte Constitucional sul-africana quanto ao direito fundamental à saúde e assuntos a ele correlatos.
\end{abstract}

Palavras-chave: Controle de Constitucionalidade. Direitos sociais. Direito à saúde. Corte Constitucional da África do Sul.

\section{INTRODUÇÃO}

A África do Sul tem recebido especial atenção nos últimos vinte anos, após o fim do regime do apartheid, em 1994. O sistema judicial do país e as decisões dos tribunais têm sido alvo de análises, em virtude, especialmente, da prioridade dada à promoção dos direitos fundamentais sociais à saúde e à propriedade.

Isso porque o período de transição política para a nova democracia, concretizada com a Constituição Democrática da África do Sul, trouxe consigo a necessidade urgente de minimizar os danos do regime de segregação racial no tocante à ausência de tratamento de saúde e de direito à terra à maioria da população.

\footnotetext{
${ }^{86}$ Mestranda no curso de mestrado acadêmico "Constituição e Sociedade" do Instituto Brasiliense de Direito Público - IDP. Pós-graduada em Direito Público pela Fundação Escola Superior do Distrito Federal e Territórios - FESMPDFT. Bacharela em Direito pelo Centro Universitário de Brasília - UniCEUB. Advogada.
} 
O direito à saúde, objeto de pesquisa deste trabalho, encontra-se previsto no artigo 27 da Constituição sul-africana, o qual preceitua que "todos têm direito à saúde, incluindo a saúde reprodutiva" e que "a ninguém pode ser negado o tratamento médico de emergência", dentro do das possibilidades financeiras do Estado ${ }^{87}$.

Em razão dos intensos debates sobre a intervenção judicial nas demais faces governamentais, buscar-se-á, por meio do presente trabalho, analisar o posicionamento do Poder Judiciário da África do Sul com o intuito de contribuir com a pesquisa acadêmica sobre os delineamentos da jurisprudência daquele país.

Optou-se pelo corte metodológico de coleta de decisões prolatadas apenas pela Corte Constitucional da África do Sul em matérias que envolvam o direito à saúde. Os filtros de pesquisa adotados serão oportunamente explicitados no decorrer deste trabalho.

Inicialmente, serão tecidas algumas ponderações acerca do contexto histórico da Constituição Democrática da República da África do Sul, e algumas considerações a ela interligadas, como o controle de constitucionalidade praticado no país.

Posteriormente, fundamentada em pesquisa jurisprudencial, será examinada a posição da Corte Constitucional sul-africana no tocante à proteção e efetivação do direito à saúde e demais assuntos a ele afetos.

\section{O CONTROLE DE CONSTITUCIONALIDADE NA ÁFRICA DO SUL}

\subsection{O sistema judicial sul-africano}

A face judicial do governo sul africano é exercida por meio dos tribunais, os quais são independentes e submetidos apenas ao crivo da Constituição e das leis ${ }^{88}$. A carta magna prevê a jurisdição dos tribunais criados por lei de inciativa parlamentar, divididos por instâncias, matérias e por território.

\footnotetext{
${ }^{87}$ Constitution of the Republic of South Africa. Art. 27. Health care, food, water and social security 1. Everyone has the right to have access to: (1) health care services, including reproductive health care; (...) 2. The state must take reasonable legislative and other measures, within its available resources, to achieve the progressive realisation of each of these rights. 3.No one may be refused emergency medical treatment.

88 Constitution of the Republic of South Africa, Chapter 8. Disponível em: <http://www.gov.za/documents/constitution-republic-south-africa-1996>. Informações detalhadas podem ser obtidas através do link <http://www.gov.za/about-government/judicial-system e http://judiciary.org.za/>
} 
Inicialmente, a Constituição sul-africana prevê a figura dos "Small Claims Courts", equiparados aos tribunais de pequenas causas no sistema judicial brasileiro. No entanto, a previsão naquele país é que os tribunais de pequenas causas julguem apenas os litígios cíveis de pequeno porte no valor de até $\$ 15.000,00$ (quinze mil randes ${ }^{89}$ ), não abarcando a seara criminal.

Por conseguinte, os Tribunais de Magistrados (Magistrate's Courts) ocupam a primeira instância para a maioria dos casos, exceto para casos mais graves e casos civis limitados a certo valor monetário mínimo. Os tribunais dividem-se por distritos judiciários e têm sua atuação delimitada pela matéria objeto do litígio, como, por exemplo, Tribunal da Criança e da Juventude, de Família, da Concorrência, Tribunal Comunitário e Tribunal Distrital de casos criminais e civis.

Por seu turno, há também os Tribunais Regionais, estabelecidos conforme os limites territoriais de cada província, perfazendo o total de nove. Tais tribunais detêm competência para julgar litígios civis, incluindo àqueles relativos à família e divórcio.

Ocupando a segunda instância judicial, a Constituição traz os Tribunais Superiores (High Courts), com jurisdição na área de atuação delimitada geograficamente, semelhante aos tribunais regionais do Brasil. Em áreas extensas, os tribunais dividem-se em filiais, havendo atualmente 13 tribunais superiores no país ${ }^{90}$. Importante mencionar, ainda, a existência de Tribunais Superiores especializados, tais como Tribunal do Trabalho, Tributário/Fiscal, Eleitoral, Tribunal de Propriedade (Juizado de Terra), da Igualdade e da Concorrência.

Equivalente ao Superior Tribunal de Justiça brasileiro, na África do Sul há o Tribunal Supremo Tribunal de Recurso, chamado também de Supremo Tribunal de Apelação. Localizado em Bloemfontein, o tribunal de recurso é a última instância para discussões acerca de matérias infraconstitucionais, cujas decisões serão vinculantes para todos os tribunais inferiores $^{91}$.

\footnotetext{
${ }^{89}$ Rand é a moeda oficial da África do Sul, a qual, conforme última cotação verificada, em 30/09/2016, equivale a 1 rand $=\mathrm{R} \$ 0,23$ (vinte e três centavos).

${ }^{90}$ Tribunal Superior de Eastern Cape, com quatro filais em Grahamstown, Port Elizabeth, Mthatha e Bisho; Supremo Tribunal Free State, em Bloemfontein; Gauteng, com filiais em Pretória (North Gauteng) e uma em Joanesburgo (Sul Gauteng); KwaZulu-Natal também com duas filiais, em Pietermaritzburg e Durban; Supremo Tribunal Limpopo em Thohoyandou; Tribunal Superior Northern Cape em Kimberley; Tribunal Superior North West em Mafikeng; e Tribunal Superior do Cabo Ocidental na Cidade do Cabo.

${ }^{91}$ A seara trabalhista é a única que possui um Tribunal de Recursos específico.
} 
Por fim, ocupando posição suprema no sistema judicial do país está a Corte Constitucional da África do Sul, órgão incumbido de solucionar apenas os litígios envolvendo normas constitucionais.

\subsection{A Corte Constitucional sul-africana e o controle de constitucionalidade}

Sediada em Joanesburgo, a Corte Constitucional da África do Sul ${ }^{92}$ foi criada em 1993 pela Constituição interina adotada após as primeiras mudanças ocorridas rumo ao fim do apartheid, regime de segregação racial institucionalizado no país desde 1948. A Corte Constitucional sul-africana é composta por onze juízes, dentre os quais insere-se o Chefe de Justiça e o Chefe de Justiça substituto ${ }^{93}$. Assim como no sistema brasileiro, são independentes e imparciais, e, assim sendo, não podem ser membros do parlamento, do governo ou estarem filiados a algum partido político ${ }^{94}$.

O acesso à Corte Constitucional pode ocorrer de diversas formas: como recurso de acórdão proferido por um Tribunal Superior ou pelo Supremo Tribunal de Recurso; recurso em caso de competência originária da Corte, em razão da urgência da matéria; recurso de acórdão de um tribunal inferior que declarou a inconstitucionalidade de uma lei; e como um projeto de lei que o parlamento pede para Corte analisar.

No tocante ao controle de constitucionalidade, da Constituição sul-africana prevê que o Tribunal Constitucional tem competência exclusiva para decidir as disputas entre órgãos estatais, poderes e funções constitucionais; decidir sobre a constitucionalidade de projeto de lei parlamentar ou provincial quando o Presidente da África do Sul ou o primeiro ministro de uma província tiver dúvidas e encaminhar o projeto para análise da Corte; sobre a

\footnotetext{
${ }^{92}$ Conforme preceitua o artigo 174 da Constituição da África do Sul, a Corte Constitucional é composta por 11 ministros, indicados pelo Presidente da República, a partir de lista tríplice elaborada pela Comissão de Serviços Judiciários, para exercerem mandato único de 2 a 15 anos sem possibilidade de revogação ou nomeação. Os requisitos para a composição da Corte são: que todos sejam cidadãos sul-africanos, que pelo menos 4 dos 11 juízes sejam juízes em outras Cortes à época da nomeação, que a composição reflita a diversidade racial e de gênero que compõem a sociedade sul-africana e, por fim, que o indicado não seja membro de parlamento, nem de partido político, a fim de assegurar a independência da Corte. Disponível em: http://www.gov.za/documents/constitutionrepublic-south-africa-1996

${ }_{93}$ Constitution of the Republic of South Africa. 167. (1). The Constitutional Court consists of the Chief Justice of South Africa, the Deputy Chief Justice and nine other judges.

${ }^{94}$ A nomeação dos juízes da Corte é feita pelo Presidente da República da África do Sul, dentre os indicados em lista que deve ser previamente elaborada pela Comissão do Serviço Judicial Ressalte-se que há entrevistas públicas antes da nomeação dos juízes, podendo o Presidente, após as entrevistas, consultar o Chefe de Justiça e os líderes dos partidos políticos com representação na Assembleia Nacional. Disponível em:

http://www.constitutionalcourt.org.za/site/judges/howjudgesareappointed.htm
} 
constitucionalidade de ato do parlamento ou da legislatura provincial, mediante a provocação de membros da assembleia nacional ou provincial; sobre a constitucionalidade de emenda à Constituição; decidir se o parlamento ou o presidente não cumpriu uma obrigação constitucional; e, por fim, certificar uma constituição provincial ${ }^{95}$.

Da análise da Constituição sul-africana, é possível perceber que o sistema judicial adota tanto o controle concentrado quanto difuso. Isso porque há casos específicos que serão levados diretamente à Corte Constitucional para a verificação de constitucionalidade, enquanto que os demais não abrangidos no rol citado alhures ficarão a cargo do controle de constitucionalidade dos tribunais inferiores. Tais tribunais poderão exercer o controle de constitucionalidade difuso, mas as decisões prolatadas não terão efeito vinculante, devendo, para isto, serem confirmadas pela Corte Constitucional, de acordo com o teor do artigo 167 (5) da Carta Magna da África do $\mathrm{Sul}^{96}$.

\section{O DIREITO À SAÚDE NA JURISPRUDÊNCIA DA ÁFRICA DO SUL}

A primeira eleição multirracial para o novo Parlamento sul-africano ocorreu em abril de 1994, ocasião na qual Nelson Mandela foi eleito para ocupar o cargo de Presidente da República ${ }^{97}$. No mesmo ano, deu-se início a elaboração da Constituição democrática da África do Sul para a substituição da Constituição interina de 1993. O texto final foi aprovado em 1996, entrando em vigor no ano seguinte.

A constituição interina de 1993/94 já previa um catálogo de direitos fundamentais e uma forma de controle de constitucionalidade. Sendo assim, antes de sua entrada em vigor a Constituição permanente foi submetida ao controle de constitucionalidade, procedimento conhecido como Certificação da República da África do Sul.

\footnotetext{
95 Constitution of the Republic f South Africa. 167. 4. Only the Constitutional Court may a. decide disputes between organs of state in the national or provincial sphere concerning the constitutional status, powers or functions of any of those organs of state; b. decide on the constitutionality of any parliamentary or provincial Bill, but may do so only in the circumstances anticipated in section 79 or 121;c. decide applications envisaged in section 80 or 122 ; d. decide on the constitutionality of any amendment to the Constitution; e. decide that Parliament or the President has failed to fulfil a constitutional obligation; or $\mathrm{f}$. certify a provincial constitution in terms of section 144.

96 (5) The Constitutional Court makes the final decision whether an Act of Parliament, a provincial Act or conduct of the President is constitutional, and must confirm any order of invalidity made by the Supreme Court of Appeal, the High Court of South Africa, or a court of similar status, before that order has any force.

${ }^{97}$ Apesar da eleição ser realizada pelo parlamento, o presidente da república exerce as funções de chefe de Estado e de Governo, razão pela qual a África do Sul pode ser considerada uma república presidencialista.
} 
O texto constitucional sul africano elenca um amplo rol de direitos fundamentais, semelhante ao da Constituição da República brasileira de $1988^{98}$. Dentre eles, destacam-se os direitos sociais à saúde, à seguridade social, ao trabalho e à moradia.

Quanto ao direito à saúde, objeto de análise deste trabalho, a Constituição da República da África do Sul prevê que todos têm acesso à tratamento de saúde e que a ninguém será negado tratamento médico de emergência ${ }^{99}$. Tais previsões encontram-se no rol do "Bill of Rights" da Constituição Sul-africana, o qual assemelha-se, em grande medida, ao rol de direitos e garantias fundamentais da Constituição Federal brasileira de 1988.

A terminologia "direitos fundamentais" está ligada a uma universalidade não mais abstrata como os direitos humanos, mas sim material e concreta. Assim, os direitos fundamentais são os direitos humanos positivados e reconhecidos pelo ordenamento jurídico sendo, portanto, originariamente, direitos humanos. (GALINDO, 2008)

Os direitos fundamentais são aqueles que detêm um nível mais elevado no tocante à necessidade de proteção e por isso, encontram-se positivados na Constituição. São aqueles advindos da evolução dos pensamentos filosóficos, políticos e religiosos, os quais colocaram o indivíduo em foco, introduzindo a ideia de "decência social mínima" (BITTAR; FERRAZ, 2008 p. 51), crescendo a busca pela dignidade da pessoa humana.

Dessa forma, diz-se que os direitos fundamentais, materialmente, são pretensões advindas do valor da dignidade humana de acordo com os diferentes momentos históricos (BRANCO; MENDES, 2014). Já em sua concepção formal, são aqueles com maior grau de garantia ou segurança constitucional, "são aqueles direitos que o direito vigente qualifica como tais". (HESSE, apud BONAVIDES, 2019, p. 560)

Sendo o direito à saúde um direito social fundamental, tem-se que ao Estado cabe não somente agir de forma negativa, no sentido de não exercer atos prejudiciais à saúde de outrem,

\footnotetext{
98 Igualdade, dignidade humana, Vida, Liberdade e Segurança da Pessoa, Proibição de escravidão, servidão e trabalho forçado, direito à privacidade, liberdade de religião, crença e opinião, liberdade de expressão, reunião, demonstração, direito de petição, liberdade de associação, direitos políticos, cidadania, liberdade de circulação e residência, liberdade de comércio, ocupação e profissão, relações de trabalho, meio ambiente, propriedade, habitação, saúde, água, alimento e segurança social, Criança, Educação, Língua e Cultura, comunidades culturais, religiosas e linguísticas, Acesso à informação, ação administrativa, acesso aos tribunais, direito das pessoas presas, detidas e acusadas. Disponível em: http://www.gov.za/documents/constitution/chapter-2-bill-rights\#7

${ }^{99}$ Constitution of the Republic of South Africa 27. Health care, food, water and social security (1) Everyone has the right to have access to - (a) health care services, including reproductive health care; (b) sufficient food and water; and (c) social security, including, if they are unable to support themselves and their dependants, appropriate social assistance. (2) The state must take reasonable legislative and other measures, within its available resources, to achieve the progressive realisation of each of these rights. (3) No one may be refused emergency medical treatment.
} 
mas também, e, principalmente, requer-se uma ação estatal positiva a fim de respeitá-lo, protegê-lo, promovê-lo e efetivá-lo.

\subsection{Esclarecimentos metodológicos}

Com o objetivo de analisar o posicionamento da Corte Constitucional sul-africana sobre o direito à saúde, passa-se, neste tópico, ao estudo da jurisprudência do Tribunal. Para tanto, as decisões foram colhidas mediante o mecanismo de busca disponível no endereço eletrônico oficial da Corte ${ }^{100}$, adotando-se os seguintes filtros: Health e Minister of Health em "keyword or case name; "cases" em "search in", e 1995 até 2015 em "year", pesquisando cada ano singularmente ${ }^{101}$.

A pesquisa jurisprudencial apresentou 15 resultados, os quais referem-se a 12 casos. Isso porque a pesquisa apresentou como decisões apartadas dois casos nos quais houve subdivisão nas publicações, quais sejam: três decisões subdividas que tratam do caso Minister of Health and Others $v$ Treatment Action Campaign and Others, e duas subdivisões da decisão do caso Minister of Health and Another $v$ New Clicks South Africa (Pty) Ltd and Others.

Cabe ressaltar, ainda, que dos 12 casos apresentados pela pesquisa, estão fora do campo amostral a ser analisado neste estudo (direito à saúde ou assuntos interligados): National

\footnotetext{
${ }^{100}$ http://www.constitutionalcourt.org.za/site/judgments/judgments.htm

${ }^{101}$ Os resultados da pesquisa apresentaram as seguintes decisões: Soobramoney v Minister of Health (KwazuluNatal) (CCT32/97) [1997] ZACC 17; 1998 (1) SA 765 (CC); 1997 (12) BCLR 1696 (27 November 1997); Minister of Health and Others v Treatment Action Campaign and Others (No 1) (CCT9/02) [2002] ZACC 16; 2002 (5) SA 703; 2002 (10) BCLR 1075 (5 July 2002); Minister of Health and Others v Treatment Action Campaign and Others (No 2) (CCT8/02) [2002] ZACC 15; 2002 (5) SA 721; 2002 (10) BCLR 1033 (5 July 2002); In Re: Certain Amicus Curiae Applications; Minister of Health and Others v Treatment Action Campaign and Others (CCT8/02) [2002] ZACC 13 (5 July 2002); MEC for Health, KwaZulu-Natal v Premier, Kwazulu-Natal: In re Minister of Health and Others $v$ Treatment Action Campaign and Others (CCT15/02) [2002] ZACC 14; 2002 (10) BCLR 1028 (5 July 2002); National Education Health \& Allied Workers Union (NEHAWU) v University of Cape Town and Others (CCT2/02) [2002] ZACC 27; 2003 (2) BCLR 154; 2003 (3) SA I (CC) (6 December 2002); Minister of Health and Another v New Clicks South Africa (Pty) Ltd and Others (CCT 59/2004) [2005] ZACC 14; 2006 (8) BCLR 872 (CC); 2006 (2) SA 311 (CC) (30 September 2005); Minister of Health and Another v New Clicks South Africa (Pty) Ltd and Others In re: Application for Declaratory Relief (CCT59/04A) [2005] ZACC 25 (30 September 2005); Affordable Medicines Trust and Others v Minister of Health and Another (CCT27/04) [2005] ZACC 3; 2006 (3) SA 247 (CC); 2005 (6) BCLR 529 (CC); Nyathi v Member of the Executive Council for the Department of Health Gauteng and Another (CCT 19/07) [2008] ZACC 8; 2008 (5) SA 94 (CC); 2008 (9) BCLR 865 (CC) (2 June 2008); $C$ and Others v Department of Health and Social Development, Gauteng and Others (CCT 55/11) [2012] ZACC 1; 2012 (2) SA 208 (CC); 2012 (4) BCLR 329 (CC) (11 January 2012); MEC for Health, Eastern Cape and Another v Kirland Investments (Pty) Ltd [2014] ZACC 6; 2013 (11) (25 March 2014); Horn and Others $v$ LA Health Medical Scheme and Another [2015] ZACC 13 (CCT 97/14) 2014 (11) (14 May 2015); Oppelt v Head: Health, Department of Health Provincial Administration: Western Cape [2015] ZACC 33 (CCT185/14) 2015 (2) (14 October 2015); Baloyi v Member of the Executive Committee for Health and Social Development, Limpopo and Others [2015] ZACC 39 (CCT227/14) (10 December 2015); Dirk Links v Member of the Executive Council for the Department of Health, Northern Cape Province (CCT29/15) 2015 (9) (awaiting trial).
} 
Education Health \& Allied Workers Union (NEHAWU) v University of Cape Town and Others; $C$ and Others $v$ Department of Health and Social Development, Gauteng and Others; MEC for Health, Eastern Cape and Another v Kirland Investments (Pty) Ltd; Horn and Others $v$ LA Health Medical Scheme and Another; Baloyi v Member of the Executive Committee for Health and Social Development, Limpopo and Others. Affordable Medicines Trust and Others $v$ Minister of Health and Others ${ }^{102}$.

Dos seis casos pertinentes ao estudo aqui proposto, Dirk Links $v$ Member of the Executive Council for the Department of Health, Northern Cape Province foi excluído da análise por encontrar-se a margem do campo amostral delimitado neste estudo ${ }^{103}$.

A seguir realizar-se-á a análise dos cinco casos remanescentes no tocante ao direito à saúde na Corte Constitucional da África do Sul.

\subsection{Soobramoney x Minister of Health KwaZulu-Natal}

O caso Soobramoney ${ }^{104}$ ocupa, mesmo após nove anos da decisão da Corte ${ }^{105}$, lugar de destaque na jurisprudência sul-africana. O requerente, do sexo masculino e com quarenta e um anos de idade, solicitava autorização para o tratamento de diálise no sistema público de saúde.

Soobramoney sofria de insuficiência renal crônica e realizava a diálise no sistema privado de saúde. Em virtude da ausência de recursos financeiros para dar continuidade ao tratamento na rede privada, o paciente recorreu ao sistema público. No entanto, o tratamento foi recusado por não cumprimento dos critérios médicos para diálise.

Sendo assim, o autor recorreu ao Tribunal Superior requerendo a autorização para fazer a diálise no sistema público. As alegações do autor perpassavam pelas violações da dignidade humana em ração do caráter injusto e discriminatório da recusa do tratamento (arts. $9^{\circ}$ e 10 ), do direito à vida (art. 11) e do direito de não ter recusado um tratamento médico de urgência (art. $\left.27, \S 3^{\circ}\right)$.

Diante de novo indeferimento, o autor interpôs recurso para o Supremo Tribunal de Recurso/Apelação. Ao analisar o caso, o ministro Combrik, relator do processo, destacou que

\footnotetext{
102 Os casos citados versam sobre limitações de competência do Ministro da Saúde, atribuições do Ministério da Saúde, licenciamento dos profissionais da saúde e afins, não contemplando o direito à saúde em si.

${ }^{103}$ Cumpre esclarecer que a pesquisa jurisprudencial incluiu o caso citado em razão da realização de audiência ainda no ano de 2015 utilizado como parâmetro para pesquisa. No entanto, o julgamento do caso ocorreu apenas em 30 de março de 2016, razão pela qual sua análise é vedada.

${ }^{104} \mathrm{O}$ inteiro teor da decisão pode ser conferido em http://www.constitutionalcourt.org.za/site/home.htm

${ }^{105}$ O julgamento ocorreu no dia 27 de novembro de 1997.
} 
os critérios médicos para a negativa do tratamento no sistema público foram estabelecidos com base nas orientações nacionais do Departamento de Saúde para os serviços estaduais de diálise. As orientações preconizavam a prioridade no tratamento de pessoas com probabilidade ou aptas a futuro transplante de rim ou tratamento diverso, e que, em razão disso, necessitavam de diálise por período curto de tempo.

Ao revés das diretrizes do Departamento de Saúde, o requerente encontrava-se em quadro insuficiência renal já em estado crônico, não abarcado pelo tratamento médico de urgência. Além disso, Soobramoney era diabético e havia sofrido um infarto no ano anterior causado por doença cardíaca isquêmica, externando ainda mais sua condição de saúde extremamente debilitada.

O Tribunal aduziu também que as demandas devem ser conciliadas com os recursos públicos, uma vez que os recursos são escassos e limitados, devendo ser observado o artigo 27 , $\S 2^{\circ}$, da Constituição sul-africana ao afirmar que as obrigações impostas pela Constituição ao Estado necessariamente dependem dos recursos correspondentes, sendo, por fim, indeferido o pleito do requerente.

De acordo com o entendimento do Tribunal, a intervenção judicial não se justificaria neste caso, pois restava clara a tentativa governamental de resolver o problema, tendo havido um "esforço sincero e racional, pleno de boa fé".

Apresentado novo recurso, o caso chegou à Corte Constitucional sul-africana, que, por seu turno, manteve o indeferimento do pedido do autor, por unanimidade de votos, com base nos fundamentos utilizados anteriormente pelo ministro Combrik.

O ministro Chaskalson, relator e presidente da Corte Constitucional, aduziu que

\footnotetext{
Não podemos deixar de ter simpatia pelo recorrente e sua família, que enfrentam a cruel dilema de ter de empobrecer-se, a fim de garantir o tratamento que o recorrente pede, a fim de prolongar a sua vida. O fato duro e desagradável é que, se o recorrente fosse um homem rico ele seria capaz de obter esse tratamento privado; ele não é, e tem de olhar para o estado a fornecer-lhe com o tratamento. Mas os recursos estados são limitados e que a recorrente não preenche os critérios para a admissão ao programa de diálise renal. Infelizmente, isso é verdade não apenas quanto ao recorrentemas de muitos outros que precisam de acesso a unidades de diálise renal ou para outros serviços de saúde. Há também aqueles que precisam de acesso à habitação, alimentos e água, oportunidades de emprego e seguro Social. Estes também são aspectos do direito à:

"uma vida humana:. o direito de viver como um ser humano, para ser parte de uma comunidade mais ampla, para compartilhar a experiência da humanidade"

O Estado tem de gerir os seus recursos limitados, a fim de resolver todas estas reivindicações. Haverá momentos em que isto será exigido para adotar uma abordagem holística em prol de necessidades maiores da sociedade, em vez de se concentrar nas necessidades específicas de determinados indivíduos dentro da sociedade. (p. 19 - tradução livre)
} 
Apesar do direito à tratamento da saúde poder, de fato, incluir pacientes em estágio crônico sem chances de cura ou melhora significativa, o $\$ 3^{\circ}$ do art. 27 da Constituição da África do Sul alberga a hipótese de tratamento de urgência, caso distinto das necessidades do

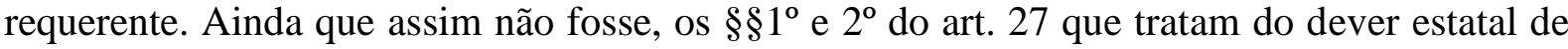
oferecer serviços de saúde a todos, impõem a limitação da disponibilidade de recursos estatais.

Pode-se observar que o poder judiciário negou, desde o início, o pedido do requerente sob o argumento de que sua condição estava fora dos critérios fixados pelo Departamento de Saúde. Para tanto, o judiciário se valeu da análise da política pública já existente para diálise renal, considerando razoáveis os critérios de admissão adotados.

3.3 Minister of Health and Others v Treatment Action Campaign and Others (No 1); Minister of Health and Others v Treatment Action Campaign and Others (No 2); In Re: Certain Amicus Curiae Applications; Minister of Health and Others v Treatment Action Campaign and Others

Julgado em 5 de julho de 2002, o caso diz respeito à prevenção da transmissão gestacional do vírus HIV (prevenção da transmissão vertical - PTV) por meio de uma droga antirretroviral $^{106}$.

O vírus HIV (human immunodeficiency vírus/ vírus da imunodeficiência humana) que conduz à AIDS (acquired imune deficiency syndromel síndrome de deficiência imunológica adquirida), é, de acordo com Plano Estratégico para a África do Sul ${ }^{107}$ o maior desafio enfrentado pelo país desde o nascimento da democracia, sendo tratado pelo governo como assunto de prioridade máxima.

Por decisão governamental, a distribuição do medicamento neviparina ${ }^{108}$, utilizado para a prevenção da transmissão vertical (PTV) da gestante para o filho, foi limitada a apenas dezoito locais-piloto na África do Sul (dois locais em cada província: 1 rural e 1 urbano). A limitação perduraria pelo prazo de dois anos, o que, de acordo com o governo, tinha por intuito garantir a segurança da terapia medicamentosa por meio do monitoramento dos efeitos colaterais do

\footnotetext{
${ }^{106} \mathrm{O}$ inteiro teor das decisões pode ser conferido em http://www.constitutionalcourt.org.za/site/home.htm ${ }^{107}$ HIV/AIDS \& STD strategic plan for South Africa 2000-2005.

108 “A nevirapina é uma acção rápida e potente droga anti-retroviral desde há muito utilizado em todo o mundo no tratamento de HIV / AIDS e registrado na África do Sul desde 1998. Em janeiro de 2001, foi aprovada pela Organização Mundial de Saúde para uso contra intraparto transmissão de mãe para filho do HIV, isto é, a transmissão do vírus de mãe para filho no momento do nascimento. Também foi aprovado para tal uso na África do Sul”. Tradução livre, p. 10.
} 
antirretroviral, bem como coletar informações para o aprimoramento da qualidade do programa de prevenção a ser futuramente estendido a todas as instituições públicas do país.

Diante da limitação imposta, a Treatment Action Campaign, juntamente com o Centro de Direitos das Crianças e com o Dr. Haroon Saloojee, ajuizaram ação no Tribunal Superior de Pretoria alegando que tal limitação ia de encontro com o direito à saúde assegurado no art. 27 da Constituição sul-africana. Os requerentes alegaram que as medidas adotadas eram deficientes por duas razões centrais: proibiam a administração de neviparina em hospitais públicos e clínicas fora dos locais-piloto, e, falhavam em implementar um programa abrangente de PTV. 109

O Tribunal Superior de Pretoria entendeu que o governo falhou na resposta para o desafio do HIV/AIDS ao promover um tratamento deficiente. Isso porque não houve razoabilidade em restringir o fornecimento de neviparina no setor público de saúde e, tampouco, em não estabelecer prazo para um programa de PTV de âmbito nacional.

A restrição do fornecimento da droga antirretroviral foi, portanto, considerada incompatível com a Constituição, a qual prevê que o Estado bem como todos os seus órgãos tornarão efetivos todos os direitos ali previstos. Além disso, a Corte Superior emitiu uma ordem declaratória sobre a obrigatoriedade de o Governo disponibilizar neviparina para as mulheres gravidas que dessem à luz no setor público de saúde e para os seus bebês.

As duas principais violações apontadas pelos requerentes foram o direito de todos a terem acesso aos cuidados de saúde no sistema público e o direito de proteção especial da criança, previstos nos artigos $27, \S 1^{\circ}$ e $2^{\circ}$, e $28, \S 1^{\circ}$, “c" da Constituição Democrática ${ }^{110}$.

Além das violações apontadas pelos requerentes, discutiu-se também se o governo era ou não constitucionalmente obrigado a "imediatamente planejar e implementar um programa nacional eficaz, abrangente e progressivo para a prevenção da transmissão de HIV de mãe para filho"111.

\footnotetext{
${ }^{109}$ Participaram como amicus curiae o Instituto para a Democracia na África do Sul, o Centro de Direito Comunitário e o Santuário de bebês de Cotlands. Os Requeridos, chamados de "respondentes", foram o Ministro da Saúde e todos os membros dos Conselhos Executivos da saúde das províncias da África do Sul.

${ }^{110}$ Constitution of the Republic of South Africa, Art. 27(1) Everyone has the right to have access to - (a) health care services, including reproductive health care; (...) (2) The state must take reasonable legislative and other measures, within its available resources, to achieve the progressive realisation of each of these rights (...) Art. 28(1) Every child has the right - (c) to basic nutrition, shelter, basic health care services and social services.

${ }^{111}$ As declarações apresentadas pelos recorrentes abordaram estas duas questões centrais de uma variedade de perspectivas especializadas, que vão desde a pediatria, farmacologia e epidemiologia ao público administração de saúde, economia e estatística. Os trabalhos também incluem a testemunho de médicos, enfermeiros e conselheiros confrontados diariamente com as tragédias humanas de HIV mães infectadas e seus bebês. Além disso, há relatos pungentes de HIV-positivos gestantes a pedidos de acesso a nevirapina para si e seus bebês em saúde pública instituições onde o seu fornecimento é proibido.
} 
Em alegações, o governo levantou questões sobre a separação de poderes, argumentando que o Poder Judiciário deveria ser deferente para com o Executivo no diz respeito às suas políticas públicas e a ordem deveria versar sobre a opinião do judiciário quanto às falhas do executivo em cumprir os deveres constitucionais. Tais considerações, segundo o requerido, eram relevantes para analisar a maneira segundo a qual os tribunais deveriam exercer os poderes constitucionalmente previstos ao judiciário, bem como para discutir a questão da justiciabilidade.

Por seu turno, os amicus curiae aduziram que a seção 27 da constituição sul-africana refere-se a um direito individual inverstido em todos. Tal direito tem um "quórum mínimo" (minimum core) de que cada pessoa é titular, segundo o Comitê das Nações Unidas sobre os Direitos Econômicos, Sociais e Culturais que é encarregado de monitorar as obrigacoes estatais constantes no Pacto Internacional de Direitos Econômicos, Sociais e Culturais.

Conforme o Comitê das Nações Unidas, se o Pacto fosse interpretado de forma a não estabelecer tal núcleo mínimo de obrigações, seria largamente privado de sua Detré raison. Da mesma forma, deve-se notar que qualquer avaliação para determinar se um Estado cumpriu as suas obrigações fundamentais mínimas deve também ter em conta as restrições de recursos disponíveis no país em questão. Cada Estado deve adotar as medidas necessárias até o máximo de seus recursos disponíveis e, portanto, demonstrar que houve um esforço para utilizar o máximo de recursos disponíveis para satisfazer, com prioridade, as obrigacoes mínimas ${ }^{112}$.

Segundo o Ministro Yacoobs J,

(...) uma leitura proposital das secções 26 e 27 não leva a qualquer outra conclusão. É impossível dar acesso a todos, mesmo a um serviço mínimo imediatamente. Tudo o que é possível, e tudo o que se pode esperar do Estado, é que ele aja razoavelmente para fornecer acesso ao direitos sócioeconomicos identificados nas seções 26 e 27 em uma base progressiva. (Tradução livre, p. 8)

No tocante ao papel dos tribunais na efetivação dos direitos assegurados constitucionalmente, o Ministro acrescentou que

(...) deve-se sempre ter em mente que os tribunais não são equipados institucionalmente para fazer amplas investigações fatuais e políticas necessárias para determinar qual é o quorum mínimo de cada direito, nem para decidir a forma mais eficaz de gasto das receitas públicas neste particular, pois há diversas demandas urgentes sobre o érario público. (Tradução livre, p. 28-30)

Yacoobs J ponderou, ainda, que

${ }^{112}$ CESCR General Comment 3 AThe nature of States parties obligations (Art. 2, par.1) 14/12/90 apud Minister of Health and Others $v$ Treatment Action Campaign and Others (No 1), p.19-20. 


\begin{abstract}
Os Tribunais não são adequadas para julgar questões em que ordens judiciais poderiam resultar em múltiplas consequências sociais e económicas para a comunidade. A Constituição prevê um papel contido e focado para os tribunais, a saber, a exigir que o Estado tome medidas para cumprir suas obrigações constitucionais e de sujeitar a razoabilidade dessas medidas a avaliação. Tal determinação da razoabilidade pode de fato ter implicações orçamentais, mas não são em si ajustar orçamentos. Desta forma, as funções judiciais, legislativas e executivas alcançar o equilíbrio constitucional adequado.

Concluímos, portanto, que a seção 27 (1) da Constituição não dá origem a uma auto permanente e aplicável direito positivo independente independentemente das considerações referidas na secção 27 (2). As secções 27 (1) e 27 (2) deve ser lido em conjunto como definindo o âmbito de direitos positivos que todo mundo tem e as correspondentes obrigações sobre o estado de respeitar, proteger, promover e cumprir esses direitos. Os direitos conferidos pelas secções 26 (1) e 27 (1), devem ter acesso aos serviços que o Estado é obrigado a fornecer em termos de seções 26 (2) e 27(2). (Tradução livre, p. 29)
\end{abstract}

A política pública governamental sobre a prevenção da transmissão vertical de HIV foi adotada com base em diversos documentos e principalmente no Plano estratégico sobre HIV/AID para a África do Sul 2000-2005, após a $13^{\text {a }}$ Conferência Internacional sobre HIV/AIDS ocorrida em julho do ano 2000, na cidade de Durban.

Este programa era para ser implementado em conformidade com o Protocolo para a prestação de um pacote abrangente de cuidados para a prevenção da transmissão mãe-filho do HIV na África do Sul (Protocol for providing a comprehensive package of care for the prevention of mother to child transmission of HIV in South Africa,). O protocolo previa um pacote abrangente de cuidados para a prevenção da transmissão de mãe para filho do HIV baseado em duas proposições: primeiro, a aceitação de que não há evidências científicas suficientes confirmando a eficácia de várias drogas anti-retrovirais para reduzir a transmissão do HIV de mãe para filho; e em segundo lugar, que existe uma necessidade de avaliar os desafios inerentes operacionais a introdução de um regime anti-retroviral para a redução da transmissão de mãe para filho do HIV na África do Sul, em ambos os ambientes rurais e urbanos.

O protocolo ponderava que o pessoal adequadamente treinado é um pré-requisito para o sucesso da implementação de qualquer programa. Para este fim, foi previsto o desenvolvimento de materiais para a formação dos funcionários, incluindo a formação em aconselhamento, testagem para HIV e as intervenções médicas e obstétricas necessárias para reduzir a transmissão de mãe para filho no momento do nascimento e outros assuntos relacionados.

O cerne do debate não era saber de os direitos socioeconômicos são judicializáveis ou não, pois claramente o são. O cumprimento dos direitos socioeconômicos deve ser interpretado 
de acordo com o contexto histórico e social do direito em debate, e, no caso, os requerentes demonstraram que as medidas governamentais adotadas para promover o acesso tratamento da PTV-HIV estava aquém das obrigações impostas pela Constituição ao Estado.

Cabe ressaltar que a implementação de um programa nacional de PTV seria, sem dúvidas, o ideal. No entanto, o litígio não discutiu se o ideal seria viável, mas se era razoável excluir o uso de neviparina nas situações com indicação médica e aconselhamento adequado.

Em decisão final, a Corte Constitucional manteve o entendimento do Tribunal Superior no sentido de que a restrição de distribuição da neviparina era uma medida rígida e inflexível, carecendo de razoabilidade, uma vez que a droga poderia ser administrada em mais locaispiloto com os recursos estatais disponíveis.

Conforme restou demonstrado em audiência realizada em maio de 2002, a restrição do uso do antirretroviral não se deu em razão do preço do medicamento, mas sim pela preocupação do governo quanto aos custos estruturais para testes, aconselhamento, fornecimento da fórmula para alimentação, de vitaminas, antibióticos e de monitoramento da mãe e do bebê durante o período de amamentação. Tais custos são relevantes para o programa nacional de PTV, mas irrelevantes para o fornecimento de uma dose única da droga antirretroviral para mãe e filho no momento do nascimento.

Além disso, a Corte emitiu ordem para que o governo, imediatamente, acabasse com a limitação de distribuição; permitisse/facilitasse/agilizasse o uso de neviparina para a prevenção da transmissão vertical - PTV nas instituições públicas quando houvesse indicação médica, a concordância do superintendente médico e o aconselhamento materno; e planejasse, se necessário, o treinamento de pessoas para o aconselhamento sobre a PTV.

No caso em comento, a Corte Constitucional mais uma vez analisou a política pública da existente, considerando-a, em parte, inadequada. No entanto, a Corte não pugnou por uma política nacional, apesar de ideal, mas sim afirmou que a restrição aos locais piloto era inconstitucional, pois havia recursos estatais a fim de possibilitar a distribuição do medicamento em dose única no momento do nascimento.

Além disso, a ordem emitida pela Corte Constitucional sul-africana revela uma decisão mandamental, na qual o judiciário vai além dos limites de sua atuação típica a fim de garantir o exercício de um direito fundamental. 
3.4 Minister of Health and Another v New Clicks South Africa (Pty) Ltd and Others; Minister of Health and Another v New Clicks South Africa (Pty) Ltd and Others In re: Application for Declaratory Relief

O litígio versou sobre a regulamentação pelo Ministério da Saúde para fixação de preços para a venda de medicamentos de acordo com a recomendação do Comitê de precificação. A validade dos regulamentos tem sido questionada pela indústria farmacêutica e tem sido objeto de decisões conflitantes entre os Tribunais Superiores e entre estes e o Supremo Tribunal de Apelação.

A Lei de Medicamentos (Medicines and Related Substances Act ${ }^{113}$ ) foi aprovada em 1965, tendo ocorrido diversas alterações desde então. Nos primeiros trinta anos de vigência da lei o principal objetivo era o controle de qualidade dos medicamentos, mas em 1997 algumas medidas foram introduzidas na legislação direcionadas a garantir medicamentos mais acessíveis a população e conferir, dessa maneira, efetividade a obrigação constitucional do Estado de prover a todos o acesso a tratamento de saúde.

Ademais, as inovações legislativas previam a substituição, sempre que possível, por medicamentos genéricos e, ainda, a criação de um Comitê de Preços para recomendar a introdução de um sistema nacional de preços.

Como esperado, as inovações legislativas foram alvo de forte oposição da indústria farmacêutica, a qual questionou a validade de inúmeros dispositivos. Apenas em 2003, após novas alterações, as medidas entraram em vigor.

Novamente, as inovações legais tiveram na indústria farmacêutica o seu maior opositor, o qual questionou, mais uma vez, inúmeros dispositivos. As principais questões levantadas pela indústria farmacêutica, em audiência ${ }^{114}$ ocorrida em maio de 2005 , referem-se ao funcionamento do Comitê de Precificação, aos procedimentos utilizados pelo Comitê, aos regulamentos promulgados pelo Ministro da Saúde e ao valor da taxa que os farmacêuticos foram autorizados a cobrar pela distribuição de medicamentos.

Por unanimidade, a Corte Constitucional entendeu que a Lei de Medicamentos permite que o controle de preços seja realizado por meio de regulamentos. Por maioria, entretanto, o tribunal considerou que a taxa de distribuição não é apropriada.

\footnotetext{
${ }^{113}$ Disponível em: http://www.saflii.org/za/legis/consol_act/marsa1965280/

${ }^{114}$ Importante esclarecer que houve, no caso, discussões procedimentais processuais que não serão abordadas neste artigo por opção metodológica. $\mathrm{O}$ inteiro teor das decisões encontra-se disponível em http://www.constitutionalcourt.org.za/site/home.htm
} 
Quanto ao Ministro da Saúde, o tribunal considerou delegações indevidas a determinação de taxa de logística sem a recomendação do Comitê de Preços a determinação anual de preços após consulta com o Comitê. Em ambos os casos, o tribunal indicou o que deveria ser incluído nos dispositivos para sanar a invalidade de ambos.

Apesar do regulamento como um todo ser válido, há uma série de disposições pormenorizadas que ficam aquém das exigências da Lei de Medicamentos. Na maioria dos casos o Poder Judiciário decidiu que os vícios podem sanados pela supressão de certas palavras e/ou pelo acréscimo de outras. Em outros casos, os defeitos relacionados com aspectos irrelevantes do regime, poderiam continuar enquanto aguardam alteração.

Especial atenção, no entanto, tem de ser dada para a invalidação das regras 10 e 11 sobre o fundamento de que a taxa de distribuição não é apropriada. O Tribunal ponderou que apesar taxa de distribuição ser considerada inadequada, a invalidação das normas neste particular não acarretará nenhuma consequência danosa ao principal objetivo do regulamento que é fazer com que os medicamentos sejam mais acessíveis por meio de um processo transparente de sistema de preços.

Sendo assim, o preço único de saída dos medicamentos deverá ser o mesmo preço praticado pelos fabricantes. Atacadistas, distribuidores e revendedores não podem também praticar preço mais elevado, mas tão somente cobrar uma taxa de distribuição, de acordo com o controle regulamentado.

De acordo com a Corte, um tribunal em processos de controle judicial pode conceder qualquer ordem que seja justa e equitativa, razão pela qual foi emitida uma ordem declaratória com pedido para que o Ministro da Saúde tomasse as providências adequadas para a publicação do regulamento, com as alterações sugeridas na decisão judicial, no prazo de sessenta dias.

3.5 Dingaan Hendrik Nyathi v Member of the Executive Council for the Department of Health Gauteng and Others

Trata-se de caso de negligência do sistema público de saúde, culminando na ocorrência de um acidente vascular cerebral - AVC em razão de um procedimento cirúrgico equivocado no Sr. Nyathi ${ }^{115}$.

\footnotetext{
${ }^{115}$ Inteiro teor disponível em http://www.constitutionalcourt.org.za/site/home.htm
} 
Durante o tratamento para queimaduras graves no Hospital Acadêmico de Pretória (e mais tarde no hospital Kalafong), o paciente sofreu um AVC como resultado de um procedimento cirúrgico incorreto, tornando-o portador de deficiência grave.

Alegando negligência, o Sr. Nyathi processou Conselho Executivo da Saúde da Província de Gauteng ${ }^{116}$ para a Saúde, Gauteng, por um montante de \$ 1.496 .000 (um milhão, quatrocentos e noventa e seis mil randes). Porém, antes da audiência para a determinação do montante, a condição médica do requerente piorou rapidamente, ocasião na qual ele requereu um pagamento antecipado de $\$ 317.700$ (trezentos e dezessete mil e setecentos randes) para cobrir suas despesas médicas e legais.

O Superior Tribunal de Pretória concedeu-lhe uma ordem para este montante. Apesar do Departamento de Saúde ter admitido a negligência estadual, não cumpriu com a medida provisória.

Posto isto, o autor requereu ao Tribunal Superior uma ordem determinando o cumprimento da decisão pelo Departamento de Saúde e declarando a insconstitucionalidade da Seção 3 da Lei de Responsabilidade Estatal que prevê a impenhorabilidade dos bens estatais ${ }^{117}$.

O Tribunal considerou que a proibição geral de processos de execução e penhora constituem uma restrição injustificada dos direitos à igualdade e acesso aos tribunais., violando os dispositivos 165 (5) e 195 (1) (f) ${ }^{118}$. Sendo assim, foi declarada a inconstitucionalidade da Seção 3 da Lei de Responsabilidade Estatal.

Consequentemente, o assunto foi submetido à Corte Constitucional da África do Sul para a confirmação da ordem. Antes da audiência principal, o Tribunal (em uma audiência urgente em 4 de Maio 2007) ordenou que o Membro do Conselho Executivo efetuasse o pagamento da quantia provisória ao recorrente.

A Corte considerou também que a secção 3 também violou os princípios da autoridade judicial, e o princípio de que a administração pública seja responsável. Assim, a Corte confirmou a declaração de nulidade constitucional, mas suspendeu a decisão por 12 meses, a

\footnotetext{
${ }^{116}$ Onde se localizam Pretória e Joanesburgo

117 Section 3 of the State Liability Act: No execution, attachment or like process shall be issued against the defendant or respondent in any such action or proceedings or against any property of the state, but the amount, if any, which may be required to satisfy any judgment or order given or made against the nominal defendant or respondent in any such action or proceedings may be paid out of the National Revenue Fund or a Provincial Revenue Fund as the case may be.

118 165.Judicial authority 5. An order or decision issued by a court binds all persons to whom and organs of state to which it applies. 195. Basic values and principles governing public administration. 1.Public administration must be governed by the democratic values and principles enshrined in the Constitution, including the following principles: f. Public administration must be accountable.
} 
fim de permitir que o Parlamento aprovasse legislação que previsse um meio eficaz de execução de decisões contra o Estado.

Madala $\mathbf{J}$ também criticou o fracasso do Estado para resolver cerca de duzentas dívidas de julgamento pendentes no momento da decisão. O Estado foi condenado a fornecer à Corte informações sobre todas as dívidas pendentes de julgamento e, ainda, apresentar um plano para a resolução rápida de todas as dívidas antes de 31 de julho de 2008, ou seja, sessenta dias após o julgamento.

3.6 Oppelt v Head: Health, Department of Health Provincial Administration: Western Cape

O caso refere-se ao direito de não ser recusado o tratamento médico emergencial ${ }^{119}$. Em março de 2002, o requerente, Charles Oppelt, 17 anos, sofreu uma lesão medular durante uma partida de rubgy, ficando severamente paralisado. Charles foi atendido e transferido três vezes de hospital até que, 12 horas após a lesão foi transferido para um hospital especializado em lesões na coluna vertebral, no qual, 13h após a lesão ocorrida durante a partida de rubgy, deuse inicio ao tratamento.

O requerente ajuizou ação de indenização no Supremo Tribunal de Cape Western contra o Departamento de Saúde, o Departamento de Western Cape e três organizações responsáveis pela administração do jogo de rubgy.

$\mathrm{O}$ tribunal rejeitou o pedido quanto as organizadoras do jogo, mas aduziu que o Departamento Estadual de Saúde falhou no atendimento do paciente. Um laudo pericial elaborado pelo Dr. Newton, cirurgião ortopédico que estava no comando, de 1998 a 2002, da Unidade Conradie de Traumatismo da medula espinhal (raquimedular), foi apresentado pelo requerente afirmando que se o procedimento fosse realizado em até 4h após a lesão medular, Oppelt provavelmente não ficaria tetraplégico.

O tribunal constatou que o Departamento foi negligente ao não encaminhar antecipadamente o paciente a um hospital especializado em lesões na coluna vertebral, a fim de possibilitar o atendimento em menos de $4 \mathrm{~h}$ da ocorrência da lesão.

Por fim, o tribunal considerou que os atrasos injustificáveis constataram a recusa de tratamento médico de emergência, constitucionalmente assegurado no art. $27, \S 3^{\circ}$ da

\footnotetext{
${ }^{119} \mathrm{O}$ inteiro teor da decisão encontra-se disponível em <http://www.constitutionalcourt.org.za/site/home.htm〉.
} 
Constituição da África do Sul, o que, denotava, portanto, a responsabilidade do sistema de saúde pelos danos causados ao requerente.

Por sua vez, o Departamento de Saúde estadual apelou para a Suprema Corte de Apelação, a qual asseverou que o paciente falhou em demonstrar a validade da prova pericial apresentada, uma vez que não houve comprovação dos métodos de probabilidade narrados pelo perito. Ademais, a Corte de Apelação entendeu que não houve comprovação de que, se atendido dentro do período de quatro horas após a lesão, o paciente provavelmente teria se recuperado, não restando comprovado o nexo de causalidade entre o tratamento fornecido e o estado do paciente.

Em recurso para a Corte Constitucional, Charles Oppelt alegou violação do direito ao tratamento médico de emergência e que a decisão do Tribunal de Apelação estava em desacordo com o entendimento da Corte Constitucional, uma vez havia precedente anterior semelhante ao caso em questão no qual a Corte endossou a "teoria das quatro horas" (atendimento em menos de $4 \mathrm{~h}$ da ocorrência da lesão) apresentada previamente em decisão do Supremo Tribunal de Apelação.

O requerido, Departamento de Saúde estadual, argumentou que não houve negligência, pois seus funcionários não tinham como saber da "teoria das quatro horas" e, mesmo que soubessem, havia protocolos que teriam impossibilitado o tratamento do paciente no hospital especializado em coluna vertebral.

Após audiência ocorrida em fevereiro de 2015, a Corte decidiu, por maioria, que as críticas levantadas contra a prova pericial eram infundadas e não mereciam prosperar, já que a "teoria das quatro horas" se baseia em teste descrito e aceito em decisão anterior do próprio Supremo Tribunal de Apelação.

Além disso, a ausência de protocolo especifico para os casos emergenciais não justificava o atraso no atendimento, o qual poderia ter sido realizado prontamente através do encaminhamento do paciente para o hospital adequado, onde provavelmente ele teria sido atendido dentro do período de quatro horas.

A corrente minoritária, encabeçada por Cameron J e Jappie AJ, concordou em parte com a conclusão de julgamento por maioria, mas diferia em dois aspectos: em primeiro lugar, Cameron J aduziu que o Sr. Oppelt não teve seu tratamento médico emergencial recusado, pois não se deve colocar peso extremo sobre as circunstâncias difíceis em que o pessoal médico trabalhava no dia da lesão do Sr. Oppelt; em segundo lugar, ponderou que o Departamento e seu pessoal não foram negligentes porque a "teoria de quatro horas" era nova, inédita e 
desconhecida por eles. Seria exigível apenas um "nível geral de conhecimento" em 2002, padrão este que a equipe médica demonstrou conhecer.

Por fim, diante do narrado, a Corte Constitucional julgou o recurso de Oppelt procedente, condenando o Departamento de Saúde a arcar com os danos do autor resultados da lesao ocorrida do jogo de rubgy.

3.7 O ponto de convergência das decisões

A Constituição sul-africana, assim como a brasileira, almeja atender os anseios sociais por representação democrática e pela garantia, efetivação e promoção de direitos fundamentais.

Da análise dos seis casos trazidos à contento neste trabalho, é possível perceber um ponto comum a todas as decisões: a análise das políticas públicas ou de planos de ações governamentais pertinentes ao direito fundamental em conflito.

No primeiro caso trazido à baila, a Corte Constitucional verificou a existência de uma política pública que trazia critérios médicos razoáveis para a prestação do tratamento de diálise renal. Houve, por parte da Corte, uma extensa análise das diretrizes do Departamento de Saúde a fim de garantir o direito a saúde previsto da Constituição da África do Sul e que culminou no entendimento de que a política pública governamental se revelava adequada, quedando-se o autor fora dos parâmetros fixados para atendimento.

No segundo caso o tribunal constatou que havia uma política pública sobre a prevenção da transmissão vertical do vírus HIV a qual foi objeto de profunda análise da Corte, com a participação de amicus curiae e vários especialistas ${ }^{120}$. Neste caso, no entanto, a Corte entendeu que a política pública trazia uma restrição injustificada dos locais de distribuição, não atendendo o núcleo mínimo de obrigações a fím de garantir, promover e efetivar o direito à saúde.

Ressalte-se que a Corte mencionou que não havia de se falar em limitação financeira porque a restrição imposta pela política pública envolvia tão somente o controle dos efeitos colaterais da vacina, havendo recursos disponíveis para a ampliação dos locais de distribuição.

A decisão foi de caráter declaratório mandamental, pois ordenou que o governo acabasse com a limitação de distribuição e permitisse/facilitasse/agilizasse o uso de neviparina para a prevenção da transmissão vertical - PTV nas instituições públicas. Demanda atenção, neste

${ }^{120}$ Ver notas de rodapé $\mathrm{n}^{\mathrm{o}} \mathrm{s} 30$ e 32. 
particular, o fato da decisão judicial ordenar, em verdade, que o governo adeque a política pública já existente a fim de efetivar o direito fundamental em questão.

Quanto ao terceiro caso, que versa sobre a regulamentação para fixação de preços para a venda de medicamentos mais acessíveis, a Corte analisou a constitucionalidade do regulamento à luz da Lei de Medicamentos e emitiu uma ordem declaratória com um pedido para que o Ministro da Saúde tomasse as providências adequadas para a publicação do regulamento, com as alterações sugeridas na decisão judicial, no prazo de sessenta dias.

Neste caso, o Judiciário sugeriu as alterações textuais que deveriam ser acatadas pelo Ministro da Saúde e fixou prazo para a publicação do regulamento cuja constitucionalidade estava em discussão, havendo, novamente, a deferência entre os poderes. Isso porque o Judiciário, ao conferir prazo para adequação do regulamento, devolve a matéria ao órgão competente, primando pela harmonia entre os poderes.

O quarto caso, sobre a responsabilidade estatal em virtude de negligência do sistema público de saúde, a Corte declarou inconstitucional o dispositivo da lei de responsabilidade estatal, suspendendo a decisão por 12 meses para a adequação da legislação pelo parlamento, o que revela, novamente, a deferência entre poderes. Ademais, fixou prazo para a apresentação de um plano de resolução de dívidas, conferindo ao poder competente a análise e planejamento de seus recursos.

No quinto e último caso, sobre a negligência do departamento estadual de saúde em prestar tratamento médico emergencial, não havia uma política pública especifica, ficando restrita a Corte a analisar os fundamentos do dispositivo constitucional sobre o tratamento de emergência e a teoria das quatro horas elaborada por um médico cirurgião.

Da análise da jurisprudência da África do Sul sobre o direito à saúde, é possível identificar de forma clara o controle judicial de políticas públicas e de atos governamentais relacionados ao direito fundamental à saúde. As decisões, por sua vez, têm adotado um caráter não meramente declaratório, mas também mandamental, ainda que de forma mais tímida, na medida em que a Corte Constitucional impôs, nos casos em que constatou a insuficiência ou inadequação da política pública, que o órgão competente adotasse as medidas necessárias.

O sistema sul africano enfrenta, assim como o brasileiro, dificuldades no tocante a efetividade dos direitos fundamentais constitucionalmente assegurados e quanto ao caráter das decisões judiciais e sua legitimidade democrática.

No entanto, o poder judiciário tem se debruçado sobre a análise não somente do direito e do dever estatal de garanti-lo, mas, principalmente, sobre quais ações estatais existem 
relacionadas ao direito discutido e de que forma ou em que medida são razoáveis e enquadramse dentro do financeiramente possível e aceitável.

Tais atitudes revelam-se proveitosas ao sistema institucional governamental, uma vez que parecem abaixar o tom das críticas quanto a ausência de legitimidade democrática da Corte e a violação da separação dos poderes. Sem adentrar a fundo no mérito da discussão, o qual requer um estudo em apartado, fato é que ao analisar as políticas públicas e ações governamentais, o judiciário devolve o poder ao próprio órgão competente para que proceda a adequação necessária a fim de dar concretude a um direito fundamental.

\section{CONSIDERAÇÕES FINAIS}

Os direitos sociais têm reclamado efetividade em seus diversos aspectos. Contudo, é ao Poder Judiciário que se nota o direcionamento da maioria das demandas a fim de dar concretude aos direitos constitucionalmente assegurados, mas não promovidos ou promovidos apenas de forma parcial pelo Estado.

Ocorre, porém que o apelo judicial para a implementação dos direitos fundamentais tem levantado posicionamentos conflitantes acerca dos contornos do princípio da separação de poderes. A ideia inicial montesquiana de contenção dos abusos de poder através da estrita observância legal parece ter evoluído para uma concepção substantiva segundo a qual o poder deve justificar o exercício de suas funções através da proteção e garantia da eficácia dos direitos e liberdades fundamentais. (ACKERMAN, 2000)

Como elemento de organização estatal, o modelo da separação de poderes foi incorporado em diversos ordenamentos jurídicos de acordo com a realidade institucional de cada país. Diante da difícil definição da densidade normativa do princípio, muito se tem discutido sobre suas limitações e interpretações.

Em quase 22 anos de constituição da república sul-africana, o Judiciário tem desenhado contornos que demanda reflexões acerca da implementação dos direitos sociais.

Sobre a égide da Constituição Democrática da África do Sul, a análise de seus contornos deve ser pautada na realidade institucional que pugna por uma interpretação jurisdicional/legal garantidora dos anseios do Estado Social de concretização dos direitos fundamentais.

Para possibilitar a compreensão dos debates e do posicionamento da Corte Constitucional sobre a implementação do direito à saúde, este estudo acadêmico-científico 
objetivou o exame do posicionamento do Tribunal em recentes demandas que versam sobre o tema.

Observa-se de maneira clara que as decisões judiciais convergem para um ponto comum: a análise pormenorizada da política pública afeta ao caso. Ao invés de pensar isoladamente no núcleo essencial do direito, adota-se a postura de pensar na melhor forma de tutelá-lo, examinando as políticas públicas governamentais através de critérios jurídicos, tais quais o da isonomia, da efetividade e da proporcionalidade entre meio e fim.

O judiciário não é visto como centro autônomo de efetivação do direito social, mas sim como um meio para aprimorar a sua tutela e efetivação perpassando por uma visão holística da função do juiz no estado democrático de direito.

Este estudo não tem o condão de avaliar o mérito da atuação do judiciário, positivo ou não, ilegítimo ou não. O que se pretende é uma análise dos procedimentos adotados pelos tribunais para a promoção dos direitos sociais, especificamente o direito à saúde.

No entanto, é cediço a necessidade de repensarmos a dogmática institucional para adequá-la à prática, aos anseios sociais, a concretização, ainda que parcial, mas na maior medida possível, dos direitos assegurados pelo constituinte nas suas quatro bases: respeitar, proteger, promover e efetivar ${ }^{121}$. A experiência sul-africana tem revelado a inviabilidade, ou talvez a dificuldade quase intransponível, de analisar os direitos sociais sem conectá-los com as políticas públicas.

\section{REFERÊNCIAS}

BARREIROS, Lorena Miranda Santos. Releitura do Princípio da Separação de Poderes à Luz da Concretização dos Direitos Fundamentais: os fluídos limites contemporâneos entre as funções legislativa e jurisdicional. Revista Jurídica, São Paulo: setembro, v. 58, n. 395, 2010.

BITTAR, Eduardo C. B.; FERRAZ, Anna Candida da Cunha (org.). Direitos Humanos Fundamentais: Positivação e Concretização. São Paulo: Saraiva, 2008.

BONAVIDES, Paulo. Curso de Direito Constitucional. 24. ed. São Paulo: Malheiros Editores, 2009.

\footnotetext{
${ }^{121}$ Constitution of the Republic of South Africa , Section 7(2) The state must respect, protect, promote and fulfil the rights in the Bill of Rights.
} 
BRANCO, Paulo Gustavo Gonet; MENDES, Gilmar Ferreira. Curso de Direito Constitucional. 10ª ed. São Paulo: Saraiva, 2014.

CONSTITUTION OF THE REPUBLIC OF SOUTH AFRICA. Disponível em: http://www.gov.za/documents/constitution-republic-south-africa-1996

FREITAS, Wesley R. S.; JABBOUR, Charbel J. C.. Utilizando estudo de caso(s) como estratégia de pesquisa qualitativa: boas práticas e sugestões. Estudo e Debate, Lajeado: v. 18, n. 2, 2011.

GALINDO, Bruno. Direitos Fundamentais: Análise de sua Concretização Constitucional. São Paulo: Saraiva, 2008.

LEAL, Saul Tourinho. A Constituição dos Direitos Fundamentais e a Esperança: da África do Sul ao $\quad$ Brasil. $\quad$ Disponível http://www.idp.edu.br/component/docman/doc_download/610-a-construcao-dos-direitosfundamentais-e-a-esperanca-da-africa-do-sul-ao-brasil

Série: Jurisdição Constitucional na África do Sul. Disponível no blog "Os Constitucionalistas": $\quad$ http://www.osconstitucionalistas.com.br/serie-jurisdicaoconstitucional-na-africa-do-sul

NETO, João Costa. A Corte Constitucional sul-africana e os direitos fundamentais: um paradigma a ser seguido? Observatório da Jurisdição Constitucional. Ano 7, no. 1, jan./jun. 2014.

NGWENA, Charles. Ngwena CG 2000. Access to Health Care as a Fundamental Right: The Scope and Limits of Section 27 of the Constitution. Journal for Juridical Science 25(1): 1-32 MONSTESQUIEU. Do espírito das leis. Trad. Roberto Leal Ferreira. São Paulo: Martin Claret, 2010.

PAUMGARTTEN, Michele Pedrosa. Constitucionalismo Transformador: o caso sulafricano. Disponível em: http://www4.jfrj.jus.br/seer/index.php/revista_sjrj/article/viewFile/334/290

SOUTH AFRICA GOVERNMENT. Judicial System. Disponível em http://www.gov.za/about-government/judicial-system 
THE CONTROL AND IMPLEMENTATION OF THE RIGHT TO HEALTH: the jurisprudence of South Africa

\begin{abstract}
This study aims to examine the control and implementation of the right to health by the judiciary in South Africa and in particular the Constitutional Court of the country. Therefore, it will be held brief overview about the historical context of the new South African democracy and the outlines of the judicial system with which it thereby made. The South African judicial system will be exposed to enable better understanding of the examined cases, and finally, the jurisprudence of the South African Constitutional Court will be analyzed regarding the fundamental right to health and issues related to it.
\end{abstract}

Keywords: Judicial Review. Social rights. Right to health. Constitutional Court of South Africa. 